\title{
Basophilic Myelocyte Count
}

National Cancer Institute

\section{Source}

National Cancer Institute. Basophilic Myelocyte Count. NCI Thesaurus. Code C135400.

The determination of the amount of basophilic myelocytes present in a sample. 